\title{
A Reliability-Based Approach to Nonrepairable Spare Part Forecasting in Aircraft Maintenance System
}

\author{
Nataša Z. Kontrec, ${ }^{1}$ Gradimir V. Milovanović, ${ }^{2,3}$ Stefan R. Panić, ${ }^{1}$ and Hranislav Milošević ${ }^{1}$ \\ ${ }^{1}$ Faculty of Sciences and Mathematics, University of Priština, Lole Ribara 29, 38220 Kosovska Mitrovica, Serbia \\ ${ }^{2}$ Serbian Academy of Sciences and Arts, Kneza Mihaila 35, 11000 Beograd, Serbia \\ ${ }^{3}$ State University of Novi Pazar, Vuka Karadžića bb, 36300 Novi Pazar, Serbia
}

Correspondence should be addressed to Nataša Z. Kontrec; natasa_radenkovic@yahoo.com

Received 31 December 2014; Revised 7 April 2015; Accepted 8 April 2015

Academic Editor: Emiliano Mucchi

Copyright (C) 2015 Nataša Z. Kontrec et al. This is an open access article distributed under the Creative Commons Attribution License, which permits unrestricted use, distribution, and reproduction in any medium, provided the original work is properly cited.

In recent times, spare parts inventory systems have been extensively researched, but most inventory models were not fully adequate due to the stochastic nature of inventory environment. This paper proposes an approach that supports decision making process in planning and controlling of spare parts in aircraft maintenance systems. Reliability characteristics of aircraft consumable parts were analyzed in order to substantiate this approach. Moreover, the proposed reliability model was used to evaluate characteristics of subassemblies and/or assemblies these parts belong to. Finally, an innovative approach for determining the total amount of parts required in inventory and underage costs, based on observing the total unit time as a stochastic process, is presented herein.

\section{Introduction}

Maintenance techniques have changed over time from correction (breakdown) to prevention by prediction and proactive continuous improvement [1]. Their main goal is to ensure that the system performs its function as intended. In order to achieve that, the efficient spare parts management is required. The lack of spare parts when they are needed leads to unexpected downtimes and irreparable loss for a company.

The aircraft are modern high-tech means of transport. They consist of a large number of components and parts. Each component is exposed to varying degrees of stress, with its own maintenance plan. Downtimes and costs can be reduced if a failure occurrence is forecasted and maintenance planned accordingly. If a spare part needed for replacement is unavailable, additional costs will occur (urgent orders, passenger accommodation costs in case of flight cancellation, etc.). Some consequences such as damage to an aviation company's reputation due to downtimes are difficult to quantify. This is why the problem of spare parts forecasting in aviation still persists. The main problem is to retain a required level of aircraft availability, that is, to provide the appropriate spare part at the right time and in the right place. The interest in inventory management has been increased in recent times but as stated in [2] the majority of airline operators and maintenance service companies felt that spare parts forecasting methods are not providing them with realistic results in practice so they tried to outguess the forecast.

Uncertainty of events, failure of equipment, and aircraft components have significant effect on their maintenance. These failures are random processes. It is not always possible to predict their occurrence. In order to minimize the aircraft downtime and increase availability, one approach is to maintain the appropriate level of spare parts. If we keep more spare parts than required, unnecessary warehousing costs will occur. In the opposite case, if their level is less than required, certain delay costs will occur. Therefore, the goal is to maintain the level of spare parts which provides minimum warehousing and delay costs on one side, while guaranteeing a high level of availability of spare parts on the other.

There are numerous research studies related to determining the required quantities of spare parts with the purpose of reducing delays and lead time. Croston [3] was one of 
the first researchers to tackle this issue. Rao [4] improved Croston's method by correcting several expressions without affecting the forecasting procedure. Syntetos and Boylan [57] criticized Croston's method because of the bias towards forecasting the required numbers of spare parts. They proposed a new method for controlling the spare parts inventory which reduces the error in spare parts forecasting. However, due to stochastic nature of demand and environment in which supplies are planned, these models fail to provide accurate results at all times. Bootstrap method was described in $[8-10]$ as a method which provides accurate results regarding the intermittent demand with fixed lead time, based on historical data on average demand in a set period of time. Ten to twelve years ago, the estimations of required number of spare parts with respect to technoeconomical issues (reliability, maintainability, life cycle cost, etc.) have rarely been considered and studied [11]. During the last decade, the reliability-based spare parts' planning has been studied extensively, especially when planning the spare parts needed for industrial systems/machines [12-14].

\section{Reliability Model}

The model proposed in this paper can be used as a backup tool for more efficient decision making for reliability-based spare parts forecasting in aircraft maintenance systems. Determining the reliability level in a scientific and objective manner can serve as basis for both reliability management and decision making process in aircraft maintenance [15].

The reliability is defined as a probability that the equipment or the system will complete a specific task under specified conditions for a stated period of time [16]. The aircraft spare parts can mostly be categorized into three types [17]: (1) Spare parts which can be rotated among any types of aircraft are called rotable spare parts; (2) spare parts with characteristics same as rotable spare parts but with lower price are called repairable spare parts; (3) spare parts that can only be used once are called nonrepairable or consumable spare parts.

This paper analyzes nonrepairable or consumable parts. They are important for aircraft maintenance systems because the demand for them is higher than for the other two types. The lack of spare parts leads to occurrence of underage costs. The underage costs are costs per unit of product in case of negative inventory level at the end of their usability period. In the opposite case, if the level of supplies is higher than required, the overage costs will occur. These costs are costs per unit of product in case of positive inventory level at the end of their usability period.

The most utilized models in reliability analysis are exponential models of reliability. The main assumption of exponential models is that the time between failures is exponentially distributed and that the failure rate is time independent. In this paper we are using Rayleigh's model [18] which is a special case of Weibull's model. They are both Increasing Failure Rate (IRF) models while exponential model is a Constant Failure Rate (CFR) model [19]. Also, there is a connection between Rayleigh's and exponential models.
If $x$ denotes exponential model parameter, transformation $\sqrt{x}$ gives us Rayleigh's model parameter which further changes the properties of exponential model.

The model proposed in this paper is based on Rayleigh's model, with the probability density function (PDF) given by

$$
p(w)=\frac{w}{\sigma^{2}} \exp \left(-\frac{w^{2}}{2 \sigma^{2}}\right)
$$

where $\sigma$ denotes the slope parameter, that is, $E\left(w^{2}\right)=2 \sigma^{2}$, $E$ denotes mathematical expected value of $w$, and $w$ denotes flight hours.

Also, the following assumptions are included in the proposed model: (1) Item price does not depend on ordering size; (2) overage costs are proportional to item price; (3) warehouse space and supplier capacity are sufficient. The known parameters used in this paper are $T_{\text {ut }}$-total unit time, that is, fleet average component life expressed in flight hours and price of such item provided by manufacturer. $T_{\mathrm{ut}}$ of each item can be expressed capitalizing on the properties of Rayleigh's model (1) as follows:

$$
T_{\mathrm{ut}}=\int_{0}^{\infty} w p(w) d w=\int_{0}^{\infty} \frac{w^{2}}{\sigma^{2}} \exp \left(-\frac{w^{2}}{2 \sigma^{2}}\right) d w .
$$

After introducing a transformation of variables, that is, $w^{2} /$ $\left(2 \sigma^{2}\right)=x$, previous expression reduces to

$$
T_{\mathrm{ut}}=\sqrt{2} \sigma \int_{0}^{\infty} x^{1 / 2} \exp (-x) d x=\sqrt{2} \sigma \Gamma\left(\frac{3}{2}\right),
$$

with $\Gamma(a)$ denoting the Gamma function [20, pp. 883-888], where $\Gamma(3 / 2)=\sqrt{\pi} / 2$. By taking into account this value, $T_{\mathrm{ut}}$ can be expressed in the following form:

$$
T_{\mathrm{ut}}=\sigma \sqrt{\frac{\pi}{2}}
$$

Finally, by expressing scale parameter $\sigma$ through the performance measure $T_{\mathrm{ut}}$, PDF of $w$ can be presented in the form

$$
p(w)=\frac{w \pi}{2 T_{\mathrm{ut}}^{2}} \exp \left(-\frac{w^{2} \pi}{4 T_{\mathrm{ut}}^{2}}\right) .
$$

The cumulative density function (CDF) of Rayleigh's distributed total unit time $F(w)$, that is, the probability that the item will not perform its function within the set time interval, can be expressed as

$$
F(w)=\int_{0}^{w} p(w) d w .
$$

Based on (5) and by a change of variables $w^{2} \pi /\left(4 T_{\mathrm{ut}}^{2}\right)=u$, integral (6) can be evaluated as

$$
\begin{aligned}
F(w) & =\int_{0}^{w} p(w) d w=\int_{0}^{w} \frac{w \pi}{2 T_{\mathrm{ut}}^{2}} \exp \left(-\frac{w^{2} \pi}{4 T_{\mathrm{ut}}^{2}}\right) d w \\
& =\int_{0}^{w^{2} \pi /\left(4 T_{\mathrm{ut}}^{2}\right)} \exp (-u) d u=1-\exp \left(-\frac{w^{2} \pi}{4 T_{\mathrm{ut}}^{2}}\right) .
\end{aligned}
$$


Now, we can determine the reliability functions $R(w)$ for each part individually, that is, probability that in the set time interval specific item will not fail as

$$
R(w)=1-F(w) .
$$

According to (5) and (8), we can define the failure rate function $\lambda(w)$ as the probability that an item will fail in the set time interval as

$$
\lambda(w)=\frac{p(w)}{R(w)} .
$$

After we determine the reliability of each individual item, we can further determine the reliability of the subassembly or assembly each part belongs to, considering them as a sequence connection of their components, as follows.

$\mathrm{CDF}$ of the Rayleigh distributed total unit time for entire system $F_{s}(w)$ is

$$
F_{s}(w)=F_{(1)}(w) F_{(2)}(w) \cdots F_{(n)}(w),
$$

where $F_{(i)}(w)$ denotes the total unit time CDF of $i$ th part of observed system. PDF of the Rayleigh distributed total time unit $p_{s}(w)$ for entire system can be determined as

$$
p_{s}(w)=\sum_{i=1}^{n} p_{i}(w) \prod_{\substack{j=1 \\ j \neq i}}^{n} F_{j}(w) .
$$

Further, reliability function $R_{s}(w)$ of the entire system can be determined according to

$$
R_{s}(w)=1-F_{s}(w),
$$

while failure rate function $\lambda_{s}(w)$ of the entire system can be determined as

$$
\lambda_{s}(w)=\frac{p_{s}(w)}{R_{s}(w)} .
$$

\section{Case Study}

In this part, we will apply the proposed model on specific data received from maintenance service of the Prince Aviation Serbia Company. Table 1 analyzes specific data for a set of consumable parts for Cessna 560XL aircraft. Based on the previously stated equations for each part individually, the reliability and failure rate in the set time interval $[0, w]$ are presented in this table. Graphical interpretations of the obtained results are illustrated in Figures 1 and 2.

Figure 2, presents the failure rate of the aircraft parts. It can be noticed that the failure rate is increasing, as expected, because Rayleigh's IFR model was observed.

Based on (12) and (13), the reliability of an entire assembly or subassembly can also be determined. Graphical description of reliability and failure rate functions of an assembly comprised of parts from Table 1 is presented in Figures 3 and 4 , respectively.

With the analysis of reliability and failure rate functions it can be concluded in which time interval (i.e., after how many

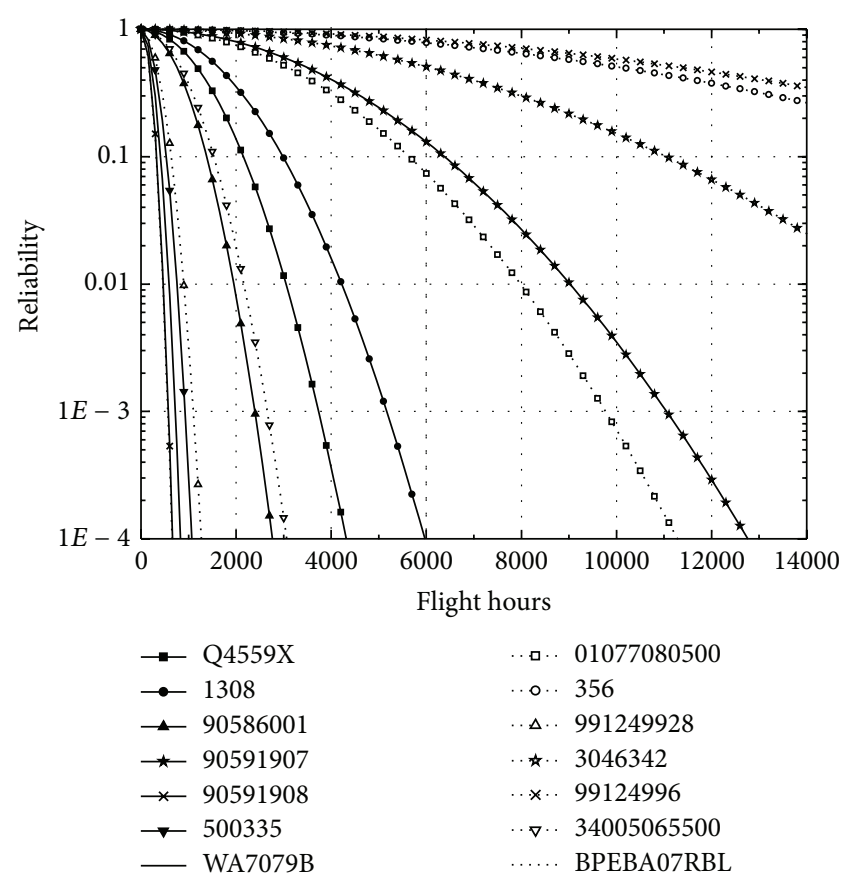

FIGURE 1: Functions of reliability of items from Table 1.

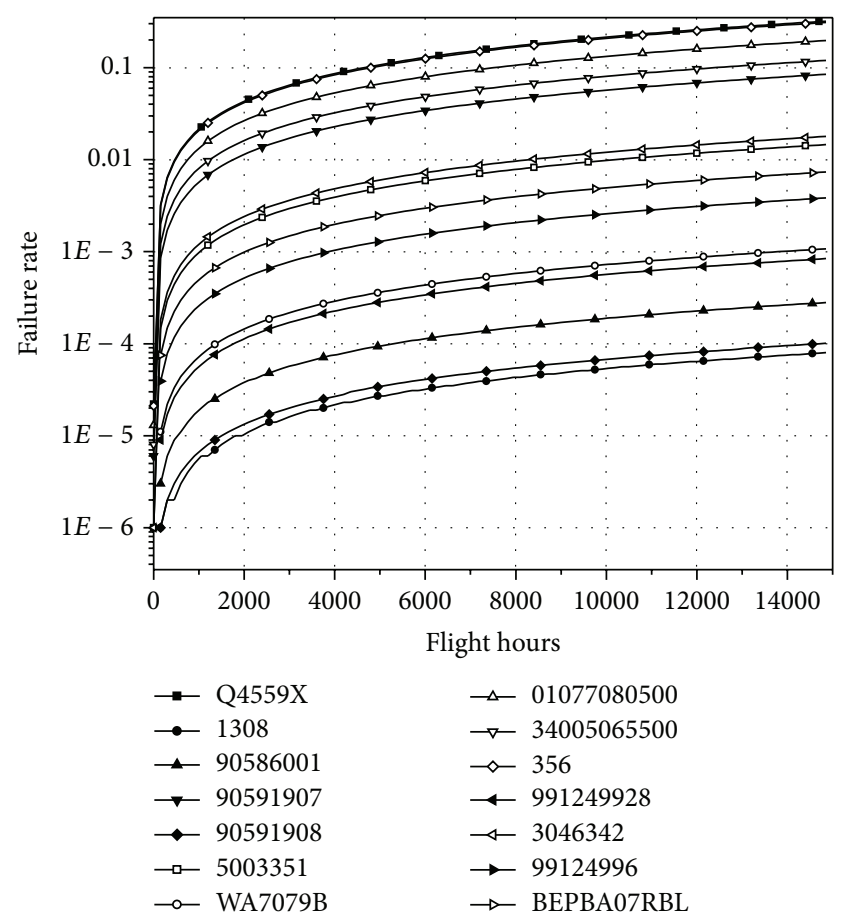

FIGURE 2: Failure rate function of items from Table 1.

flight hours) it is highly probable that a component will fail. The selection of inspection time points and condition-based maintenance (CBM) can be performed based on determining thresholds for failure rate and/or reliability, by following various well-known methods (cf. [21, 22]). For example, in [22], the conditional failure probability is calculated for observed interval and compared to the optimal threshold 
TABLE 1: Analyses of reliability characteristics of specific data.

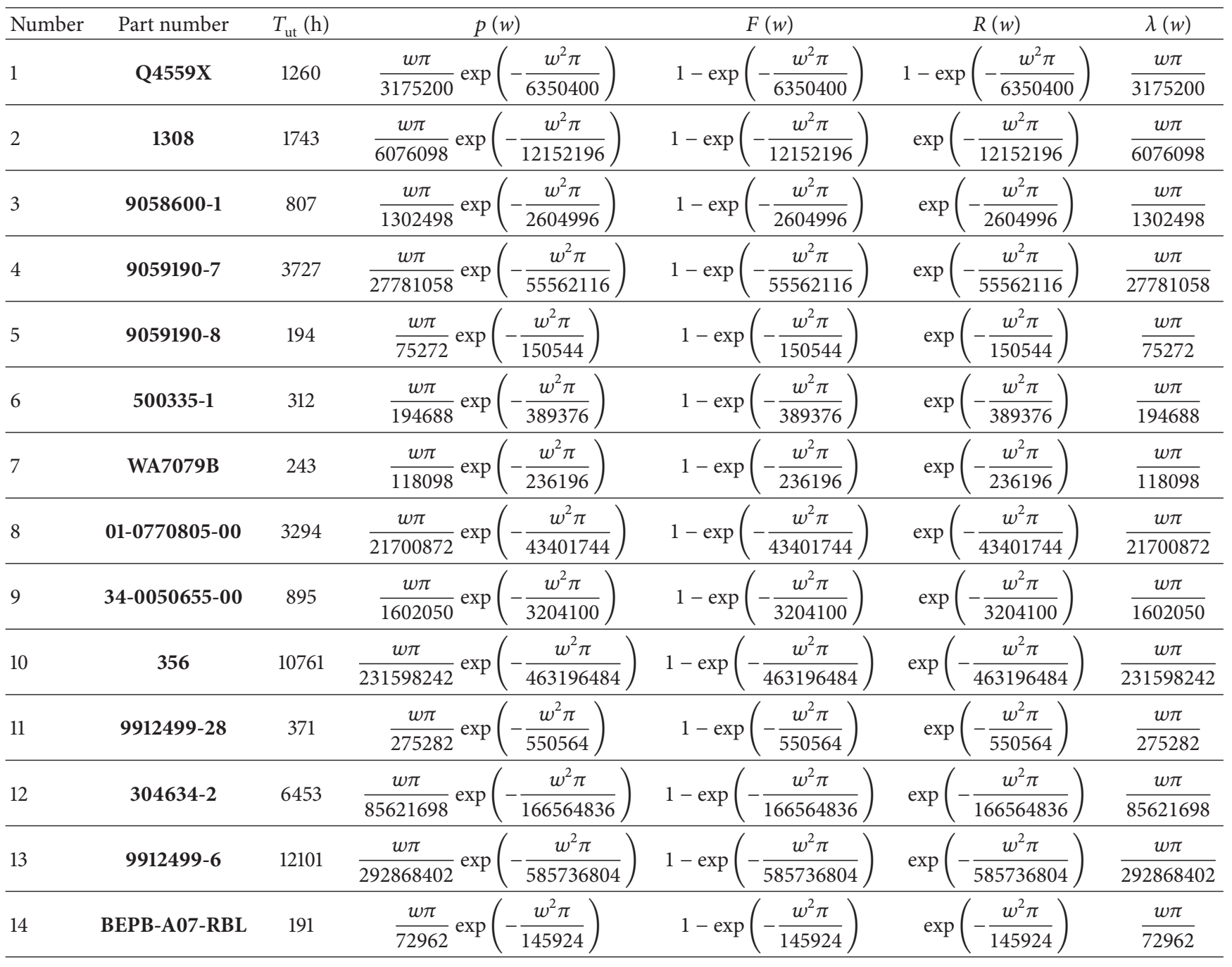

failure probability that corresponds to the lowest cost and is determined according to described CBM optimization. Based on the comparison, preventive replacement could be made. An appropriate inspection policy is also required to guarantee a satisfactory level of availability. Tracking of aircraft flight hours and analysis of failure rate function can help make a decision in which point of time a specific item is required to be in inventory.

\section{Method Presentation and Evaluation}

The additional major contribution of this work is presenting a new approach for determining the quantity of spare parts and underage costs based on the total unit time and the overage costs of an observed part. The costs that occur due to the lack of spare parts are hard to measure and they are usually assessed only. These assessments are not simple and it is hard to achieve the objective result. Some consequences of the lack of spare parts, such as damage to company's reputation because of delayed deliveries, are hard to express in cost in general.

The approach will be obtained by capitalizing on random nature of total unit time of each part. Let us here observe the expected number of variations of this random variable within an interval $\left(T_{\mathrm{ut}}, T_{\mathrm{ut}}+d T_{\mathrm{ut}}\right)$, for a given slope $\dot{T}_{\mathrm{ut}}$ within a specified open neighborhood $d T_{\text {ut }}$. Namely, if we observe given $T_{\text {ut }}$ for $N$ unit parts, then $n$ presents the number of parts that will be exposed to failure in the $T_{\text {ut }}$ and can be obtained according to the following:

$$
\begin{aligned}
n & =\int_{0}^{+\infty} p\left(w \mid \dot{T}_{\mathrm{ut}}\right) p\left(\dot{T}_{\mathrm{ut}}\right) d \dot{T}_{\mathrm{ut}} \\
& =\int_{0}^{+\infty} p(w) \dot{T}_{\mathrm{ut}} \frac{1}{\sqrt{2 \pi} \dot{\sigma}} \exp \left(-\frac{\dot{T}_{\mathrm{ut}}^{2}}{2 \dot{\sigma}^{2}}\right) d \dot{T}_{\mathrm{ut}}
\end{aligned}
$$

By a change of variables, $\dot{T}_{\text {ut }}^{2} /\left(2 \dot{\sigma}^{2}\right)=u$, the previous integral reduces to

$$
n=p(w) \frac{\dot{\sigma}}{\sqrt{2 \pi}} \int_{0}^{+\infty} \exp (-u) d u
$$




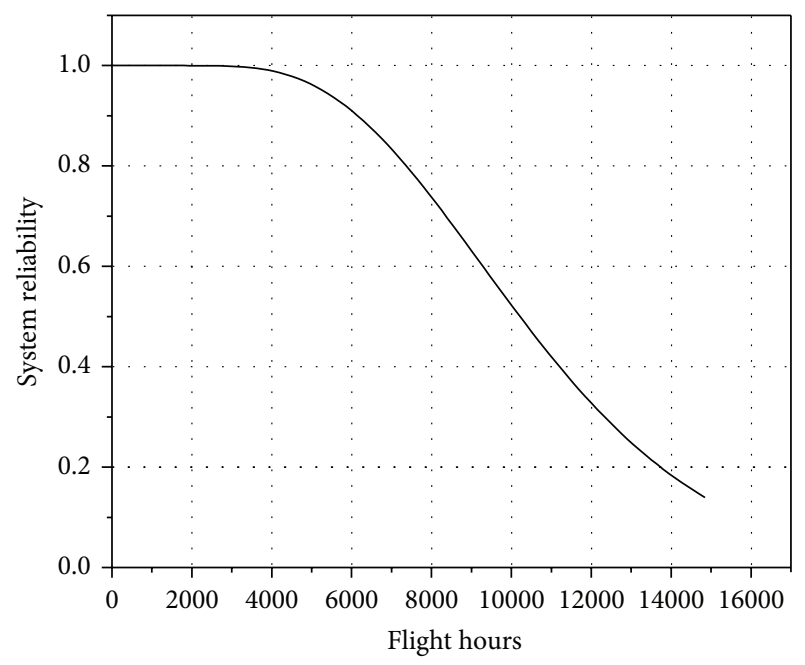

Figure 3: System reliability function.

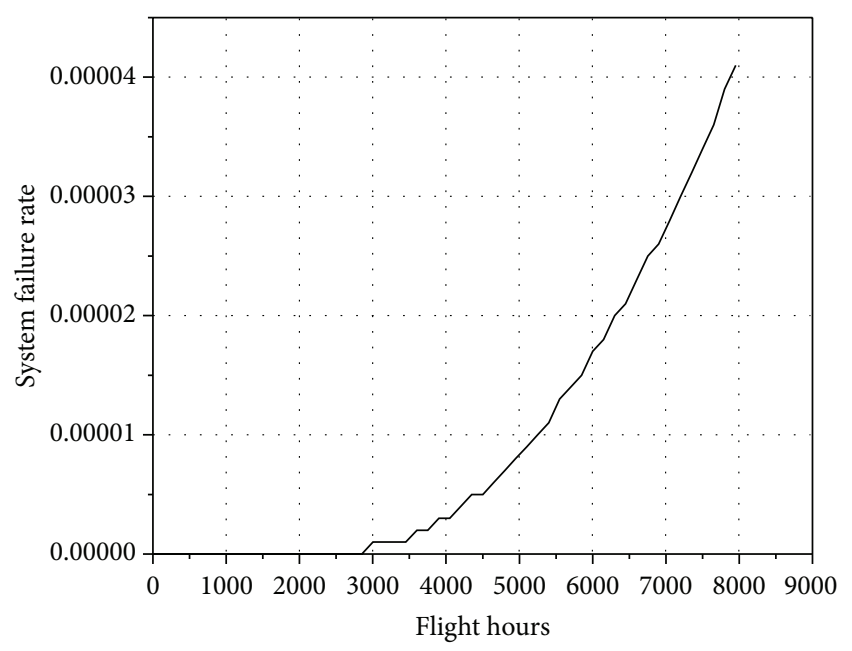

FIGURE 4: System failure rate function.

that is,

$$
n=p(w) \frac{\dot{\sigma}}{\sqrt{2 \pi}}
$$

since $\dot{T}_{\mathrm{ut}}$ is observed as Gaussian-distributed random process with variance $V\left(\dot{T}_{\mathrm{ut}}\right)=\dot{\sigma}$.

Now by taking into account the fact that $w$ is Rayleigh distributed random variable with parameters $E(w)=T_{\text {ut }}$ and $V(w)=2 T_{\mathrm{ut}}^{2} / \pi$, then the average number of parts $n$ that will be exposed to failure in the $T_{\mathrm{ut}}$ can be further expressed as

$$
n=\sqrt{2} T_{\mathrm{ut}} p(w)=\frac{w \pi}{\sqrt{2} T_{\mathrm{ut}}} \exp \left(-\frac{w^{2} \pi}{4 T_{\mathrm{ut}}^{2}}\right) .
$$

After we determine $n$, that is, the average number of parts to fail in time interval $T_{\text {ut }}$, we can also determine the total amount of parts that need to be in stock, by taking into account the expected amount of time when observed random

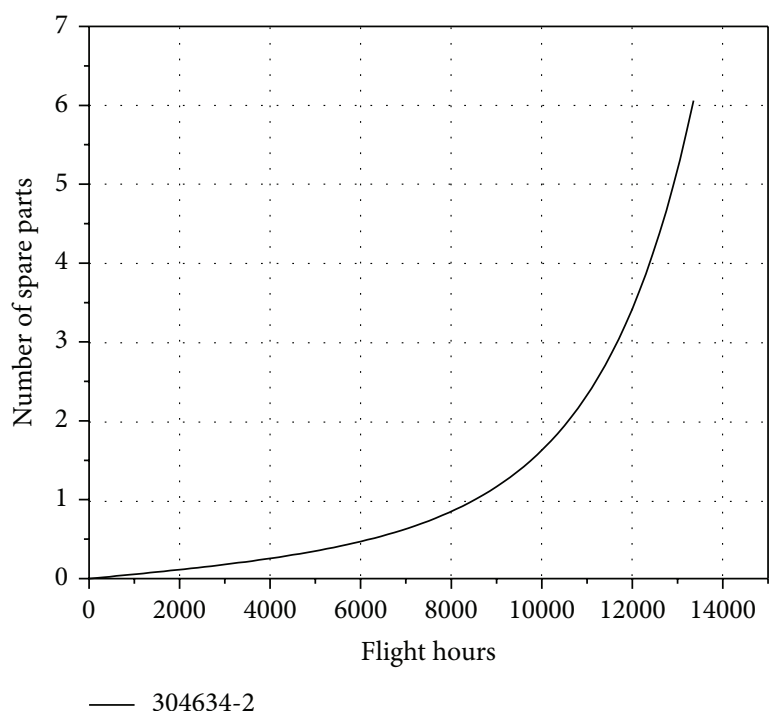

FIGURE 5: Number of spare parts in function of time for part 3046342 .

variable $w$ is below $T_{\text {ut }}$, as a quotient of CDF of the Rayleigh distributed total unit time and $n$, as

$$
q=\frac{F(w)}{n}=\frac{1-\exp \left(-w^{2} \pi / 4 T_{\mathrm{ut}}^{2}\right)}{\left(w \pi / \sqrt{2} T_{\mathrm{ut}}\right) \exp \left(-w^{2} \pi / 4 T_{\mathrm{ut}}^{2}\right)}
$$

If we implement (18) on a specific part given in Table 1 , for example, part number 304634-2, igniter plug, with $T_{\text {ut }}=6453$ flight hours, the number of spare parts can be determined as described in Figure 5.

As stated in Figure 5, after we determine in a routine control that the igniter plug has worked for more than $7000 \mathrm{~h}$, ordering that particular part and having it in inventory are required. Inspection points were selected uniformly in the $\left[T_{\mathrm{ut}}-\sigma, T_{\mathrm{ut}}+\sigma\right]$ interval, and one of inspection points for the igniter plug was obtained at $7000 \mathrm{hr}$. Such analysis can be conducted for each consumable part of the aircraft and for applying various selection algorithms for defining inspection points.

Moreover, in order to determine the underage costs which are, as stated above, difficult to evaluate, we will be using Newsvendor model. Newsvendor model can be used in all situations where the assessment of stochastic variable is required. Such assessment is a compromise between losses in case where the value of random variable is overstated and losses which are consequences of understated values of random variables. This takes place in purchase of spare parts which have no mass production, such as aircraft or weapons. Then, delivery of spare parts is arranged and often delivered together with equipment they belong to in terms of maintenance [23]. According to Newsvendor model [24], the optimal number of spare parts can be determined as

$$
q=\Phi^{-1}\left(\frac{c_{u}}{c_{u}+c_{o}}\right)
$$




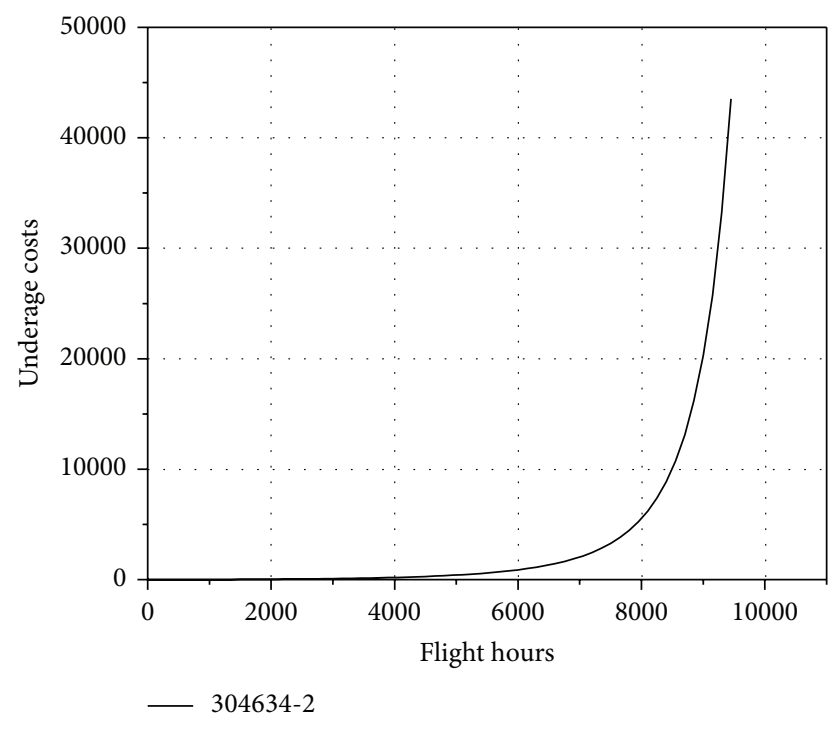

FIGURE 6: Underage costs in function of time for spare part number 304634-2.

where $\Phi^{-1}$ is the inverse of the CDF (also called the inverse distribution function), $c_{o}$ is overage costs, and $c_{u}$ is underage costs.

As we previously determined $q$, according to (19) and assuming that the overage costs are equal to supply costs of a specific spare part, we can further determine the underage costs for that part. In our example, the supply costs for spare part number 304634-2, which is an igniter plug, are $\$ 1.925,00$ while the underage costs in the function of time can be presented as in Figure 6.

As we can notice from Figure 6, the underage costs are growing exponentially in relation to time. This approach can be applied to any other consumable aircraft spare part.

\section{Conclusion}

An approach for calculating standard system performances of aircraft parts required in maintenance process was elaborated in this paper. This approach was then used to analyze the reliability characteristics of subassemblies and/or assemblies these parts belong to. In order to minimize downtimes and/or delays, a novel approach for determining the required quantities of spare parts in inventory, based on observing the total unit time as a stochastic process, was presented. Furthermore, how the presented model could be used in conjunction with Newsvendor model in the process of predicting the underage costs was elaborated. As demonstrated in method evaluation, we could calculate reliability, failure rate, number of parts exposed to failure, and underage costs, for each aircraft part in selected inspection point. These parameters are crucial for planning of maintenance actions and spare parts needs, taking into account the fact that an aircraft operator can incur costs of approximately $\$ 50,000$ for each hour if a plane is on the ground [25]. Analyzing the obtained parameters by using the presented approach could greatly support the decision making process in inventory management, especially in small aircraft companies with their own maintenance units.

\section{Conflict of Interests}

The authors declare that there is no conflict of interests regarding the publication of this paper.

\section{Acknowledgment}

This work is supported in part by the Serbian Ministry of Education, Science and Technological Development, Projects nos. \#OI 174015, \#TR 35030, and \#III 44006.

\section{References}

[1] C. Horváth and Z. Gaál, "Operating maintenance model for modern printing machines," Acta Polytechnica Hungarica, vol. 5, no. 3, pp. 39-47, 2008.

[2] A. A. Ghobbar and C. H. Friend, "Aircraft maintenance and inventory control using the reorder point system," International Journal of Production Research, vol. 34, no. 10, pp. 2863-2878, 1996.

[3] J. D. Croston, "Forecasting and stock control for intermittent demands," Operational Research Quarterly, vol. 23, no. 3, pp. 289-303, 1972.

[4] A. V. Rao, "A comment on: forecasting and stock control for intermittent demands," Operational Research Quarterly, vol. 24, no. 4, pp. 639-640, 1973.

[5] A. A. Syntetos and J. E. Boylan, "On the bias of intermittent demand estimates," International Journal of Production Economics, vol. 71, no. 1-3, pp. 457-466, 2001.

[6] A. A. Syntetos and J. E. Boylan, "The accuracy of intermittent demand estimates," International Journal of Forecasting, vol. 21, no. 2, pp. 303-314, 2005.

[7] A. A. Syntetos and J. E. Boylan, "On the stock control performance of intermittent demand estimators," International Journal of Production Economics, vol. 103, no. 1, pp. 36-47, 2006.

[8] Z. Hua and B. Zhang, "A hybrid support vector machines and logistic regression approach for forecasting intermittent demand of spare parts," Applied Mathematics and Computation, vol. 181, no. 2, pp. 1035-1048, 2006.

[9] J. H. Bookbinder and A. E. Lordahl, "Estimation of inventory re-order levels using the bootstrap statistical procedure," IIE Transactions, vol. 21, no. 4, pp. 302-312, 1989.

[10] M.-C. Wang and S. Subba Rao, "Estimating reorder points and other management science applications by bootstrap procedure," European Journal of Operational Research, vol. 56, no. 3, pp. 332-342, 1992.

[11] B. Ghodrati, Reliability and operating environment based spare parts planning [Ph.D. thesis], Luleå University of Technology, Luleå, Sweden, 2005.

[12] B. Ghodrati, P.-A. Akersten, and U. Kumar, "Spare parts estimation and risk assessment conducted at choghart iron ore mine: a case study," Journal of Quality in Maintenance Engineering, vol. 13, no. 4, pp. 353-363, 2007.

[13] A. Barabadi, B. Ghodrati, J. Barabady, and T. Markeset, "Reliability and spare parts estimation taking into consideration the operational environment-a case study," in Proceedings of the IEEE International Conference on Industrial Engineering and 
Engineering Management (IEEM '12), Hong Kong, December 2012.

[14] B. Ghodrati, D. Banjevic, and A. K. S. Jardine, "Developing effective spare parts estimations results in improved system availability," in Proceedings of the Annual Reliability and Maintainability Symposium: The International Symposium on Product Quality and Integrity (RAMS '10), pp. 1-6, January 2010.

[15] H. W. Wang and J. Gao, "A reliability evaluation study based on competing failures for aircraft engines," Eksploatacja i Niezawodność, vol. 16, no. 2, pp. 171-178, 2014.

[16] C. E. Ebeling, An Introduction to Reliability and Maintainability Engineering, McGraw-Hill, New York, NY, USA, 2009.

[17] A. D. Aisyati, W. A. Jauhari, and C. N. Rosyidi, "Determination inventory level for aircraft spare parts using continuous review model," International Journal of Business Research and Management, vol. 4, no. 1, pp. 1-11, 2013.

[18] H. Wang and H. Pham, Reliability and Optimal Maintenance, Springer Series in Reliability Engineering, Springer, 2006.

[19] W. R. Blischke and D. N. P. Murthy, "Probability distributions for modeling time to failure," in Reliability: Modeling, Prediction, and Optimization, John Wiley \& Sons, Hoboken, NJ, USA, 2000.

[20] I. Gradshteyn and I. Ryzhik, Table of Integrals, Series and Products, Academic Press, 1980.

[21] B. Wu, Z. Tian, and M. Chen, "Condition-based maintenance optimization using neural network-based health condition prediction," Quality and Reliability Engineering International, vol. 29, no. 8, pp. 1151-1163, 2013.

[22] Z. Tian, B. Wu, and M. Chen, "Condition-based maintenance optimization considering improving prediction accuracy," Journal of the Operational Research Society, vol. 65, no. 9, pp. 14121422, 2013.

[23] S. Krcevinac, M. Čangalović, V. Kovačević-Vujčić, M. Martić, and M. Vujošević, Operaciona Istraživanja 2, Fakultet organizacionih nauka, Univerzitet u Beogradu, Belgrade, Serbia, 2013, (Serbian).

[24] A. V. Hill, The Newsvendor Problem, Clamshell Beach Press, 2011.

[25] A. A. Ghobbar and C. H. Friend, "Evaluation of forecasting methods for intermittent parts demand in the field of aviation: a predictive model," Computers \& Operations Research, vol. 30, no. 14, pp. 2097-2114, 2003. 


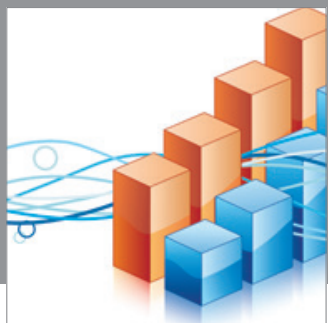

Advances in

Operations Research

mansans

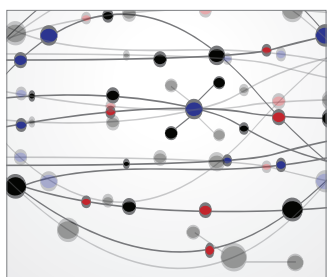

The Scientific World Journal
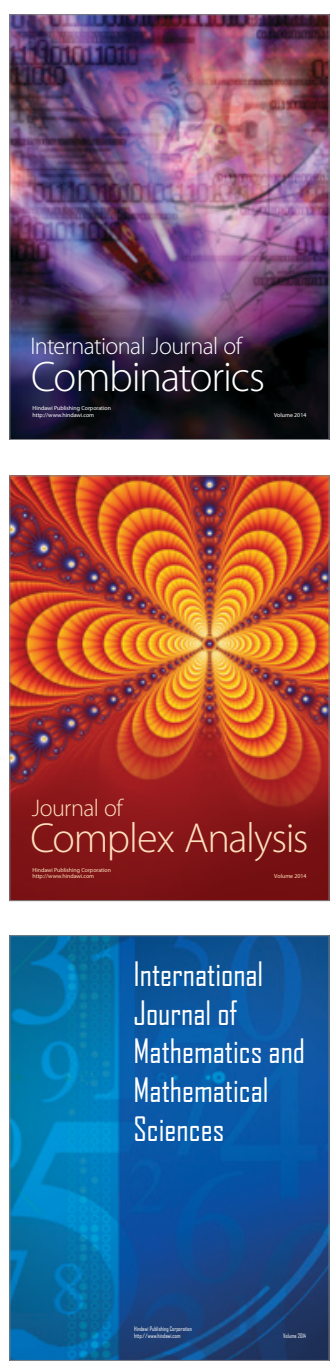
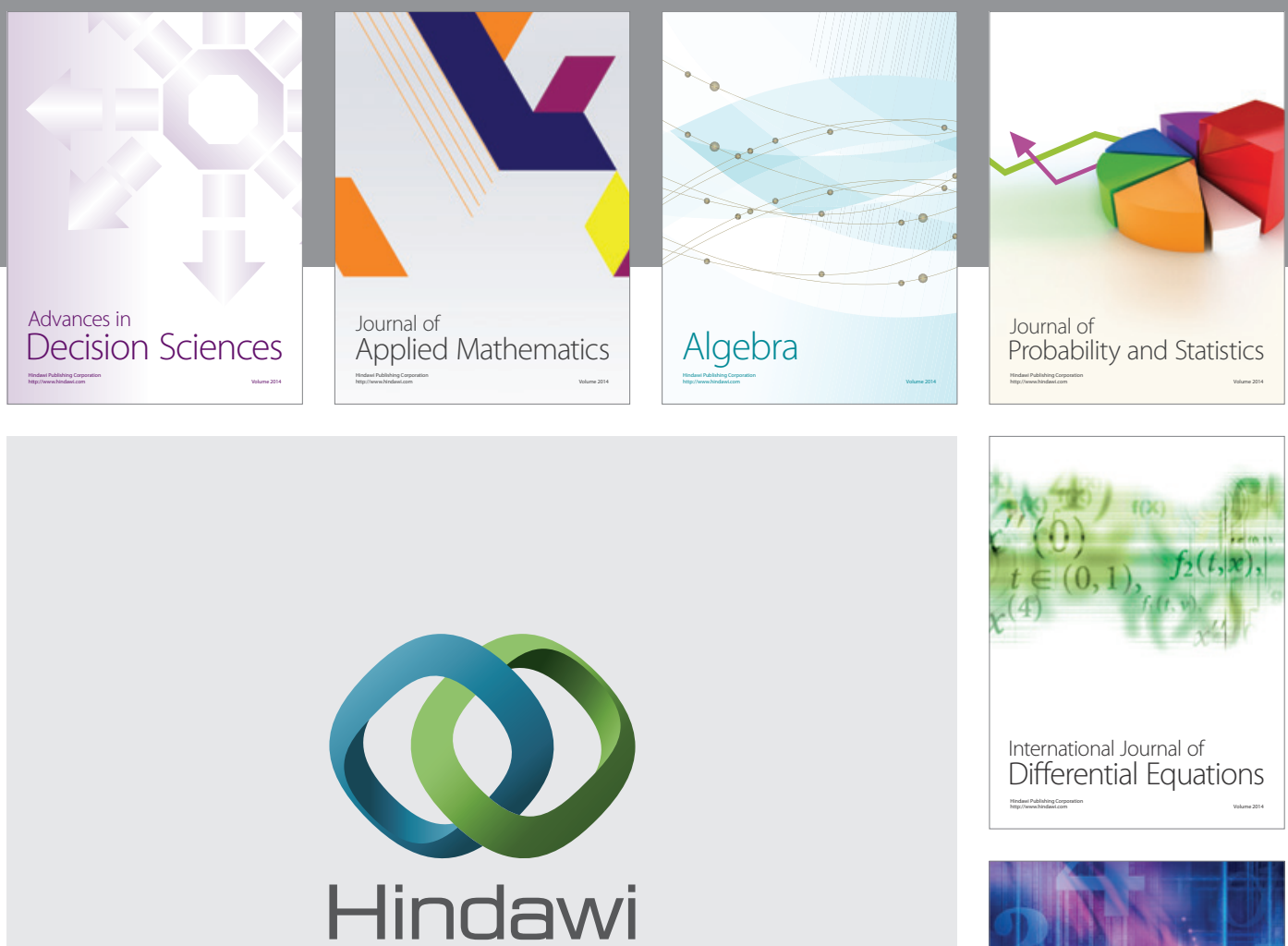

Submit your manuscripts at http://www.hindawi.com
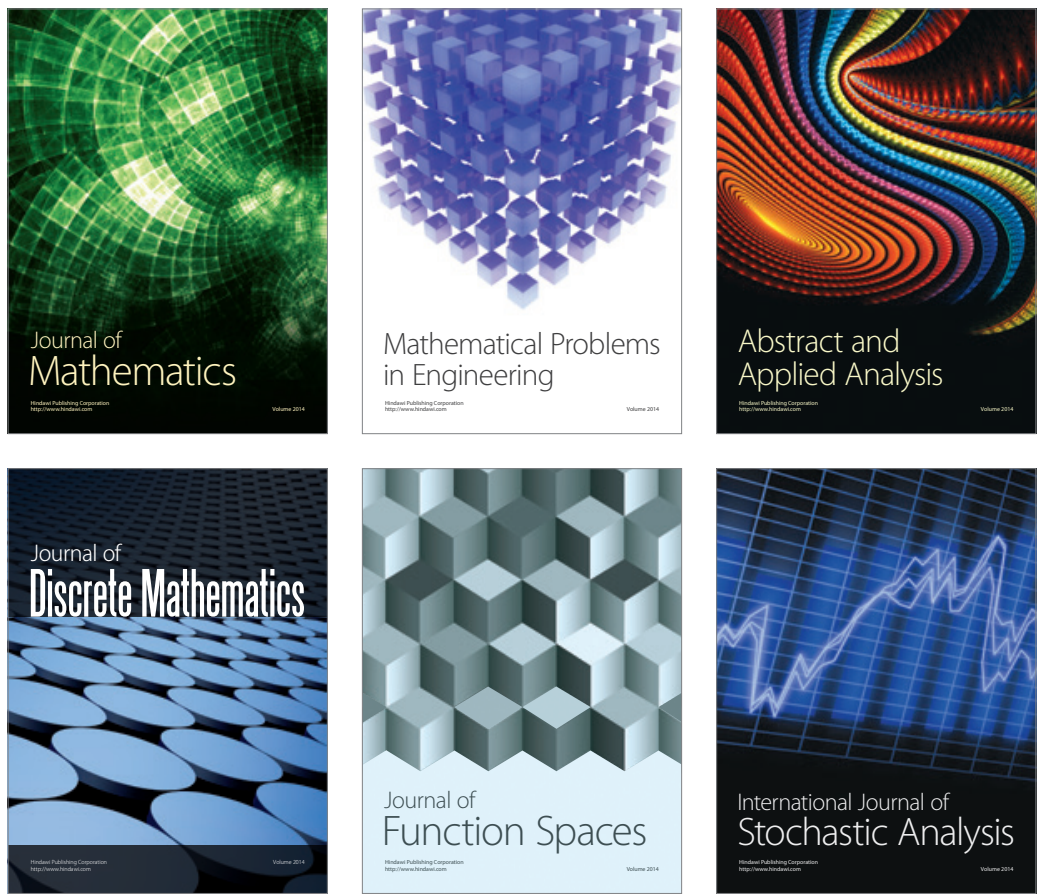

Journal of

Function Spaces

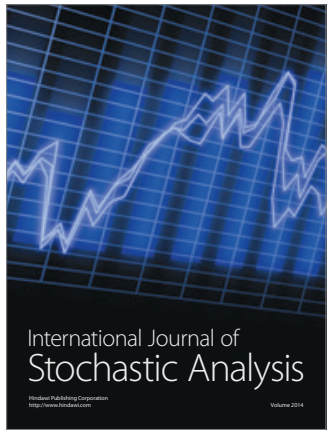

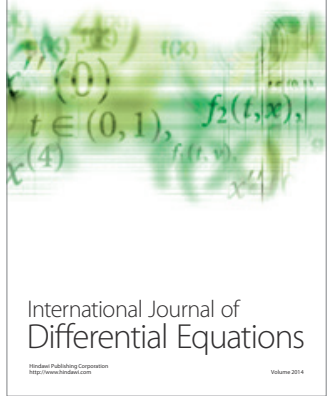
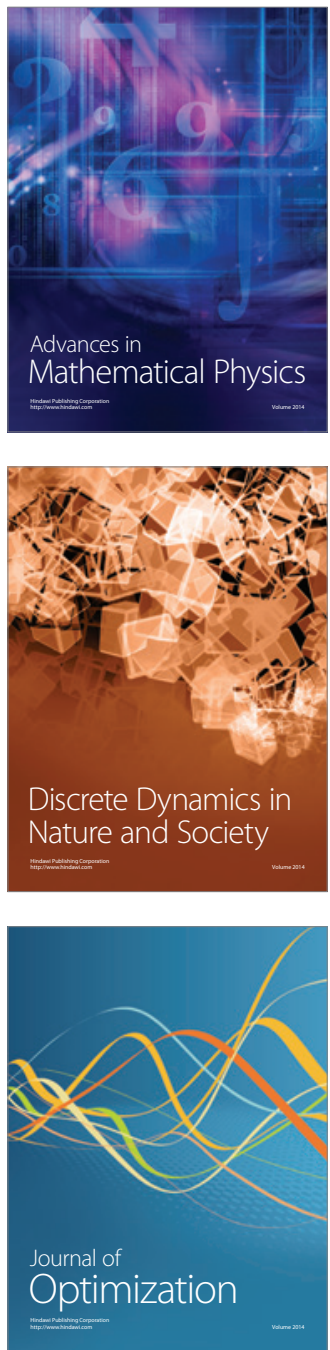